\title{
Several Hotspots Analysis and Development Trend of Chemical Engineering Technology
}

\author{
Zhengyang $\mathrm{Yi}^{1}$, a) \\ ${ }^{1}$ School of Chemistry and Chemical Engineering, Shanghai Jiao Tong University, Shanghai \\ 200240, China. \\ a) yizhengyang1703@163.com
}

Keywords: Hotspots, Trend, Chemical engineering

\begin{abstract}
With the rapid development of society and the continuous progress of science and technology, China's chemical industry also develops rapidly. The development of chemical industry also cannot do without a more in-depth study of the chemical engineering technology. Research progress and hot spot in the chemical engineering were depicted in this paper. Operating units such as supercritical chemical reaction, separation process and heat transfer process had been studied. The research emphases on chemical process, equipment, research object, studying methods and ways have been changed profoundity. Also the paper has pointed out the development trend of chemical engineering technology.
\end{abstract}

\section{INTRODUCTION}

Chemical engineering refers to the study of chemical related technology, it will be involved in research, optimization and improvement of the original equipment and also it can be the production management, operation control, environment protection, simulation system, strengthen the equipment, product development, design and Research on these aspects of the experimental process, can be said to be a chemical or a the whole process of physics. There are a lot of chemical engineering involved in the field, such as inorganic chemistry, organic chemistry, chemical and chemical engineering technology field, so to a certain level for the economic development of our country is very helpful. Of course, the study of chemical engineering technology is based on the reduction of environmental pollution, resource conservation for the purpose of research, laying the foundation for sustainable development in china.

\section{HOTSPOTS ANALYSIS OF CHEMICAL ENGINEERING TECHNOLOGY}

\section{Chemical supercritical reaction technology}

Chemical supercritical reaction technology is said that in the production of chemical reaction, temperature and pressure are beyond the critical point, such as chemical reactions usually occur in the form of liquid or gas. At present, this technology is widely used in biochemistry, food, medicine and other areas, and has a good production efficiency, the development prospects are very good. However, there are still some deficiencies, in recent years, we have been in the initial stage of the technology research, the development rate is very slow, but also to strengthen in-depth study [1-3].

\section{New research on separation technology}

The key role of separation technology is to strengthen the production equipment and realize the production technology, through the continuous innovation of production equipment, and to achieve the goal of improving production efficiency. At the same time, the separation technology was studied, and the separation of various materials was completed under different boiling conditions. Along with the development of science and technology, the research in separation process, gradually began to the application of information technology, which greatly enhance the prediction of thermodynamic equilibrium level, through the artificial establishment of molecular, promote the efficiency and speed of separation [4]. 


\section{Green chemistry research technology}

For gradually accelerate the process of industrialization, environmental pollution problems have worsened, people gradually pay more attention to the ecological environment problems, in the production process using a variety of science and technology to reduce the release of pollutants, therefore, green chemistry technology which people love and attention. In the process of production and operation of green chemical technology refers to, through the application of this technology, can better deal with the production process of pollutants, and reduce harmful, toxic substances released. At present, the most commonly used, the most obvious green chemical technology is atomic technology, while ensuring the benefits and economic, but also can strengthen social and environmental benefits [5, 6].

\section{DEVELOPMENT TREND OF CHEMICAL ENGINEERING TECHNOLOGY}

\section{Close combination of systematic procedure and chemical process study}

Because most of the chemical substances are unstable, so that the reaction process is very complex, there are many imbalances and asymmetry and so on several aspects of the characteristics. This makes the difference between people's thinking inertia is very large, the reason is because the structure of scale and control factors. The research on chemical engineering technology is to simplify the engineering structure and to enhance the value of the technology. Make use of the special and complex system to carry on many kinds of research, through the analysis, the summary then obtains the general conclusion. This is the theoretical basis for simplifying the structure, so as to achieve an effective basis for analysis, to achieve technical improvements and optimization. For example, can use integral method and reduction method etc., to adequate understanding and control system to transform, after thinking in many ways or is and who has been pushing, with time and space, to complete the transformation process problems, this can be the chemical engineering complex becomes simple, is conducive to promoting the combination of chemical process and process system. It can speed up the application of chemical engineering, substantive and value has been significantly strengthened, at the same time, to effectively complete the theoretical exploration to the direction of the practice of change. Therefore, it is necessary to complete the combination of chemical technology, computer, physics and mathematics to promote the course of Chemical inquiry [7-9].

\section{To promote the combination of materials science and chemical process research}

If companies want to produce new products or equipments, then science and technology will be widely used so that the production of technological innovation, we must continue to achieve the perfection and optimization of chemical engineering technology. Thus, can form a new industry, can also provide better services, and finally form a new, complete theoretical conclusion, so as to promote the development of chemical engineering technology to speed up. In order to realize the development of chemical engineering and technology effectively, explore the new trend of development, it is necessary to increase the cross and overlap between the various disciplines, such as speeding up the combination between environmental and chemical, energy and chemical, biological and chemical information and chemical, to develop more new materials, and promote the further development of chemical process technology. This is the chemical engineering technology research and development direction of new generation [10].

\section{Close integration of information engineering and chemical processes}

With the rapid development of information technology, various industries have a wide range of applications. As for the hot topic of chemical engineering technology, it is necessary to participate in information engineering, information engineering and chemical processes closely linked to the main characteristics of information engineering. Information engineering, can be saved to collect effective information, and information on careful analysis and research, conclusions and rules, can give the full basis for various industry business activities. Using this method, the production 
efficiency and benefit can be improved effectively. Therefore, the combination of information engineering and chemical process is the main trend of the development of chemical process technology and the key problem in this field [11].

\section{CONCLUSION}

In summary, along with the development of science and technology, greatly promote the development of chemical process technology, people are more and more mature chemical process technology. From the beginning of the single device research, the study of a single chemical process has become the field of chemistry related research. Moreover, people in the development of the industry has also taken note of the rapid development of the industry on the environment, green chemistry, resource conservation and environmental pollution is the main development direction of chemical engineering. In the process of production and operation, increasing application of chemical engineering technology, clearly harmful, toxic pollution, reducing emissions of pollutants, and reduce the environmental pollution, protect the ecological environment, promoting sustainable human survival and development. With the application of chemical engineering technology and related increases gradually, make people understand the toxic and harmful pollutants, reduce pollutant emissions, environmental pollution can be reduced a lot, one can protect the ecological environment from destruction, on the other hand can also promote the sustainable development of human beings.

\section{REFERENCES}

[1] Zhao H, Shao L, Chen J F. High-gravity process intensification technology and application[J]. Chemical Engineering Journal, 2010, 156(3):588-593.

[2] Jing L. Introduction of supercritical fluid technology[J]. Chemistry Teaching, 2004(Z2):32-33.

[3] Wei Y. Study on the development and optimization of Chemical Engineering Technology [J]. Private Science and Technology, 2014, 07:127.

[4] Ximing C, Hong P. Several hot spots and development trend of Chemical Engineering Technology[J]. Anhui Chemical Industry, 2006, 01:3-6.

[5] Gang H, Zhe S. Application of micro chemical technology in chemical Engineering[J]. China Science and Technology Expo, 2012(34):326-326.

[6] Renjie W. Application of chemical engineering technology in chemical production[J] North Engineering Management, 2016:0880

[7] Xingyu X. Analysis of the characteristics of development of technology of chemical industry and chemical engineering[J]. Journal of Chifeng University (Natural Science Edition) , 2013, 11: 1-2.

[8] Lu G, Hao Z. The promotion of green chemical engineering and technology to chemical industry[J]. 2015, 17:107.

[9] Boxun J, Fei L. pplication of green chemical technology in Chemical Engineering[J]. Chemical industry in Tianjin, 2015,03:10-11.

[10]Matlack A. Some recent trends and problems in green chemistry[J]. Green Chemistry, 2003, 5(1):G7-G12.

[11]Webb P B, Sellin M F, Kunene T E, et al. Continuous flow hydroformylation of alkenes in supercritical fluid-ionic liquid biphasic systems[J]. Journal of the American Chemical Society, 2003, 125(50):15577-88. 